\title{
Discrimination of black-capped chickadee (Poecile atricapillus) chick-a-dee calls produced across seasons
}

\author{
Erin N. Scully ${ }^{1}$, Kimberly A. Campbell ${ }^{2}$, Jenna V. Congdon ${ }^{1}$, and Christopher B. Sturdy ${ }^{*, 1,2}$ \\ ${ }^{1}$ Department of Psychology ${ }^{\text {a }}$, University of Alberta \\ ${ }^{2}$ Neuroscience and Mental Health Institute ${ }^{\mathrm{b}}$, University of Alberta \\ *Corresponding author (Email: csturdy@ualberta.ca)
}

Citation - Scully, E. N., Campbell, K. A., Congdon, J. V., \& Sturdy, C. B. (2020). Discrimination of black-capped chickadee (Poecile atricapillus) chick-a-dee calls produced across seasons. Animal Behavior and Cognition, 7(2), 247-256. doi: https://doi.org/10.26451/abc.07.02.14.2020

\begin{abstract}
While black-capped chickadees (Poecile atricapillus) primarily produce fee-bee songs in spring, they produce chick-a-dee calls year-round with call production peaking in the fall. This call serves multiple functions, including food location, flock communication, and predator alarm. As seasons change, the meaning of the call may also change. For instance, flock communication could be more important in the fall than in the spring, and food type and availability change according to season. To determine if the chick-a-dee call varies acoustically across seasons in a predictable manner, we conducted an operant go/no-go discrimination task that examined black-capped chickadees' ability to categorize calls produced in two different seasons: fall and spring. We found that birds trained to respond to vocalizations produced in either fall or spring learned to discriminate at the same rate as birds trained to respond to pseudorandomized stimuli, suggesting that none of the groups demonstrated category learning, relying instead on rote memorization. These results suggest that while chickadees can be trained to discriminate between chick-a-dee calls produced in different seasons, they do not discriminate these calls or perceive these calls as being members of natural, preexisting, perceptual categories, based on an underlying perceptual similarity.
\end{abstract}

Keywords - Acoustic discrimination, Black-capped chickadee, Operant conditioning, Season, Songbird

Animals employ numerous modes of communication, including auditory, visual, chemical, electrical, tactile/thermal, and vibration signals (Bradbury \& Vehrencamp, 1998). Birds, like many other animals, use auditory signals to communicate both within and between species groups. Vocal learners are a unique group of animals (including humans, hummingbirds, and dolphins) that require a tutor to learn vocalizations. Songbirds (of the Oscine suborder of Passeriformes) are unique from non-Passeriformes in that they are vocal learners and are capable of producing more complex vocalizations than non-songbirds due to their unique use of the vocal organ, the syrinx (Greenewalt, 1968). Songbirds produce two types of vocalizations, calls and songs, which differ in both form and function. Calls are typically acoustically simple in structure and are used for localizing food, contact between individuals, and alerting others to predators (Ficken \& Witkin, 1977; Mahurin \& Freeberg, 2009; Templeton et al., 2005). Songs tend to be more acoustically-complex than calls and are mostly reserved for mating and territory defense purposes (Ficken et al., 1978; Smith, 1991). Unlike the calls of most songbird species, the namesake chick-a-dee call produced by black capped chickadees (Poecile atricapillus) is actually more structurally-complex than the species' fee-bee song. The fee-bee song consists of two notes that are produced in a stereotyped fashion (Ficken, et al., 1978). 
Using operant go/no go discrimination tasks, Hahn and colleagues $(2015,2016)$ have shown how black-capped chickadees perceive songs differently depending on information about the signaler. For example, when provided with male and female songs, chickadees are able to discriminate between the sex of the signaler (Hahn et al., 2015). In another experiment, when provided with songs produced by chickadees in Ontario versus chickadees in British Columbia, chickadees were able to discriminate between songs produced in different geographic regions (Hahn et al., 2016). Thus, through these two experiments, it has been demonstrated that there are acoustic differences that vary sufficiently in the feebee song to indicate sex and the geographic region of the signaler.

In contrast to the simplicity of the chickadee fee-bee song, the chick-a-dee call consists of four note types that are produced in a fixed order $(\mathrm{A} \rightarrow \mathrm{B} \rightarrow \mathrm{C} \rightarrow \mathrm{D})$, though note composition and the overall number of notes can change (Ficken et al., 1978). This call serves a role in maintaining flock cohesion and communicating the location of food sources, as well as a warning of the presence of predators and recruiting con- and heterospecifics to mob nearby predators (Smith, 1991). With all the previous work conducted on the perception of the fee-bee song, the question of how chickadees perceive differences in calls remains unanswered. A recent study by Congdon and colleagues (2019) showed that when provided with mobbing calls produced in response to high-threat and low-threat predators, chickadees were able to discriminate between these vocalizations based on the level of arousal contained within the call (i.e., threat posed). This study provided insight into how chickadees perceive and respond to differences in calls produced under imminent contexts (e.g., predator threat), but how chickadees respond to differences in calls produced in additional varying contexts, such as season, remains untested.

The chick-a-dee call is produced regardless of season by both males and females with a peak in production occurring in the fall (Figure 1; Avey et al., 2008, 2011). Due to changes in food supply and social structure across seasons, we are able to assume that the information contained in the chick-a-dee call might also change. In the spring, winter flocks, which typically range from two to twelve adult chickadees, break up for members to find mates and produce offspring (Smith, 1991). Changes in hormones have been shown to alter song production and call perception in other songbirds depending on seasons, suggesting there may be a perceptual difference in chickadee chick-a-dee calls as well (Alward et al., 2017; Cynx et al., 2005; Rodriguez-Saltos et al., 2018). Just prior to and during the breeding season, it has been found that many songbirds have relatively low mobbing rates, suggesting that mobbing predators may increase the risk of an unsuccessful breeding (Shedd, 1983). However, in the summer, when birds are raising their young, mobbing rates are highest in response to conspecific calls. The findings of Shedd (1983) contradict those of Dutour and colleagues (2019) who found higher rates of mobbing in winter in response to heterospecific calls. Since chick-a-dee calls function in flock cohesion, this may be one driving force underlying why chick-a-dee call production peaks during fall.

Due to these potential differences in call use across seasons, we predicted that there may be corresponding differences in acoustic structure or delivery (syntax) that black-capped chickadees could attend to in order to discriminate between chick-a-dee calls produced in the fall versus calls produced in the spring. Based on previous success with the operant go/no-go task in determining acoustically-distinct categories perceived by chickadees (e.g., Congdon et al., 2019; Hahn et al., 2015, 2016), we conducted an operant go/no-go discrimination task using male and female chick-a-dee calls produced in two different seasons (fall and spring), and tested in a third (winter), to investigate if black-capped chickadees could first learn to categorize the calls by season, then generalize those categories to previously nondifferentially rewarded stimuli. In order to control for responding to individuals, we tested additional calls produced in the fall by individuals that also provided calls produced in the spring, and recorded all subjects' responding to these same individual/different season calls. 


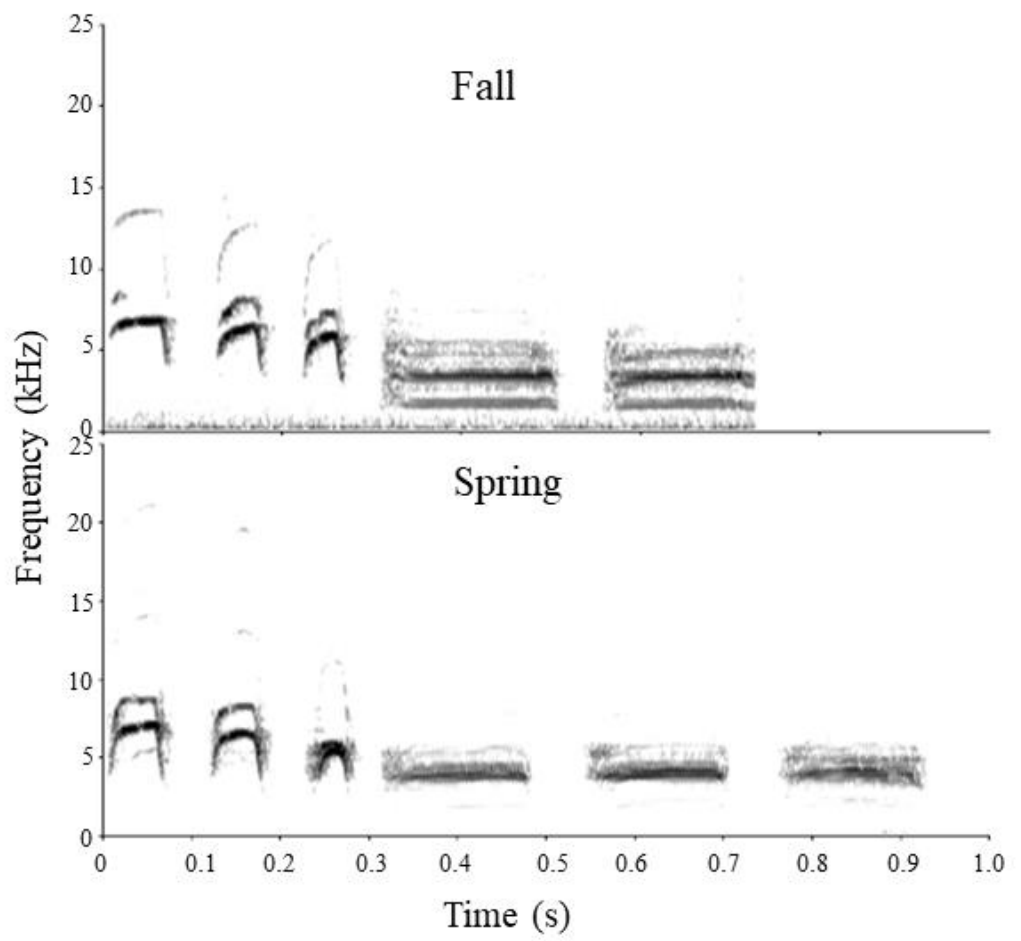

Figure 1. Spectrograms of calls produced in fall and spring. Male black-capped chickadee chick-a-dee calls produced by two different individuals. Total duration is $1 \mathrm{~s}$.

\section{Method}

\section{Subjects}

Eighteen black-capped chickadees (nine male, nine female; sex determined via DNA analysis of blood samples; Griffiths et al., 1998) were caught between January and February, 2016. These subjects had previous experience on other acoustic discrimination tasks, but not in discriminating conspecific chick-a-dee calls. All chickadees were at least one year of age at time of capture (determined by examining the color and shape of their outer tail rectrices; Pyle, 1997) in Edmonton (North Saskatchewan River Valley, $53.53^{\circ} \mathrm{N}, 113.53^{\circ} \mathrm{W}$, Mill Creek Ravine, $\left.53.52^{\circ} \mathrm{N}, 113.47^{\circ} \mathrm{W}\right)$ and Stony Plain $\left(53.46^{\circ} \mathrm{N}\right.$, $\left.114.01^{\circ} \mathrm{W}\right)$, Alberta, Canada.

During the experiment, chickadees were housed individually in operant chambers (see Apparatus below) and maintained on a natural light:dark schedule for Edmonton, Alberta, Canada for the winter season (December 21, 2016 to March 20, 2017). Birds had free access to water, cuttlebone, and grit, and were given one superworm (Zophobas morio) twice daily as nutritional supplementation. Correct responding during the operant discrimination task was rewarded with the presentation of food (Mazuri Small Bird Maintenance Diet; Mazuri, St. Louis, MO, U.S.A.), which also acted as the birds' daily food allowance. This research was conducted with the approval of the University of Alberta Animal Care and Use Committee for Biosciences, meeting the standards of the Canadian Council on Animal Care.

\section{Apparatus}

For the duration of the experiment, chickadees were housed in individual modified Jupiter Parakeet cages (30 x 40 x $40 \mathrm{~cm}$, Rolf C. Hagen, Inc., Montreal, QC, Canada) inside a ventilated, sound 
attenuating chamber. Each cage had a water bottle, a cuttlebone, a grit cup, and three perches. An opening $(11 \times 16 \mathrm{~cm})$ on the side of the cage provided each chickadee access to a motor-driven feeder (see Njegovan et al., 1994 for feeder details). Infrared cells in the feeder and on the request perch (the perch closest to the feeder) monitored the position of the bird. A personal computer connected to an experiment controller board scheduled trials and recorded responses to stimuli. Stimuli were played from the personal computer hard drive, through either a Cambridge A300 Integrated Amplifier, Cambridge Azur 640A Integrated Amplifier (Cambridge Audio, London, England), or an NAD310 Integrated Amplifier (NAD Electronics, London, England) and through a Fostex FE108 $\Sigma$ or Fostex FE108E $\Sigma$ full-range speaker (Fostex Corp., Japan; frequency response range 80-18,000 Hz) located beside the feeder. See Sturdy and Weisman (2006) for a detailed description of the apparatus.

\section{Acoustic Stimuli}

A total of 250 black-capped chickadee chick-a-dee calls were used as stimuli in the experiment, with 140 calls produced in the fall and 110 calls produced in the spring. To avoid the possibility of an individual stimulus influencing the experiment, 22 male and female individuals provided 110 of the calls produced in fall and 21 different male and female individuals provided the 110 calls produced in spring (hereby referred to as Fall 1 and Spring). The remaining 30 calls produced in the fall were provided by six individuals that had also provided spring-produced calls; however, these fall-produced calls were used only in a transfer stage to investigate possible individual effects (i.e., Fall 2). All stimuli were bandpass filtered (400 Hz-13,000 Hz; outside the frequency range of each vocalization type) using GoldWave version 5.58 (GoldWave, Inc., St. John's, NL, Canada) to reduce any background noise. For each stimulus, $5 \mathrm{~ms}$ of silence was added to the leading and trailing portion of the vocalization. The first $5 \mathrm{~ms}$ of the vocalizations were tapered to remove transients, then the amplitude was equalized using SIGNAL 5.10.24 software (Engineering Design, Berkeley, CA, USA). Stimuli were presented at approximately 75 $\mathrm{dB}$ as measured by a Brüel \& Kjær Type 2239 (Brüel \& Kjær Sound \& Vibration Measurement A/S, Nærum, Denmark; A-weighting, slow response) decibel meter at the approximate height and position of a chickadee's head when on the request perch.

\section{Acoustic Analysis}

We measured multiple acoustic features using SIGNAL software, including the $F_{(\max )}$ of the entire call, duration, number of individual note types, and the total number of notes per acoustic stimulus. We then ran multiple independent samples $t$-tests for each of the measures between calls produced in fall versus spring. We found that there were no significant differences between calls produced in the fall versus the spring for the following measures: $\mathrm{F}_{(\max )}(t(248)=1.373, p=.171,95 \% \mathrm{CI}[-116.13,650.47])$, duration $(t(248)=-1.308, p=.192,95 \%$ CI [-240.05, 48.45]), A-notes $(t(248)=-1.350, p=.178,95 \%$ CI $[-0.92,0.17])$, B-notes $(t(248)=-0.957, p=.339,95 \%$ CI $[-0.51,0.18])$, C-notes $(t(248)=-1.015, p=$ $.311,95 \%$ CI $[-0.38,0.12])$, D-hybrid notes $(t(248)=1.756, p=.08,95 \%$ CI $[-0.1,0.16])$, and D-notes $(t(248)=-1.615, p=.108,95 \% \mathrm{CI}[-1.11,0.11])$. However, we did find that there were significantly more notes per call in spring compared to fall calls $(t(248)=-2.881, p=.004,95 \%$ CI $[-1.85,-0.35])$.

\section{Procedure}

\section{Pretraining}

Once birds learned to use the request perch and feeder to obtain food, they were moved onto Pretraining. In Pretraining, birds were trained to respond to all stimuli (future $\mathrm{S}+, \mathrm{S}-$, and transfer stimuli) and received food for all responses. Each trial started with a bird landing on the request perch and remaining between 900 and $1100 \mathrm{~ms}$. A randomly selected stimulus was played without replacement until all 250 stimuli had been heard. If the bird entered the feeder within the $1 \mathrm{~s}$ interval after the stimulus 
stopped playing, it was given access to food for $1 \mathrm{~s}$, followed by a $30 \mathrm{~s}$ intertrial interval with the houselight on. If the bird left the request perch before the entire stimulus played, the houselight would turn off for a $30 \mathrm{~s}$ timeout, and the trial would be considered interrupted. If the bird sat on the perch for the full length of the stimulus, but then did not move off the perch for the $1 \mathrm{~s}$ after, a $60 \mathrm{~s}$ intertrial interval was started; however, the intertrial interval was terminated if the bird left the perch.

Birds were required to stay on pretraining until they had completed six 500 -trial blocks of $\geq 60 \%$ responding on average to all stimuli, at least four 500-trial blocks $\leq 3 \%$ difference in responding to future S+ and S- stimuli, and at least four 500-trial blocks $\leq 3 \%$ difference in responding to each transfer stimuli type (Fall 1, Spring, Fall 2). Once criteria was reached, each bird was given a day of free feed, followed by a second round of pretraining where they only needed one 500 -trial block of $\geq 60 \%$ responding on average to all stimuli, one 500-trial block $\leq 3 \%$ difference in responding to future $\mathrm{S}+$ and S- stimuli, and one 500-trial block $\leq 3 \%$ difference in responding to each transfer stimuli type (Fall 1, Spring, Fall 2).

\section{Discrimination Training}

The procedure was the same as during Pretraining; however, only the 120 training vocalizations were presented (with the remaining 130 withheld for use during transfer testing), and responding to half of these vocalizations were then punished with a $30 \mathrm{~s}$ intertrial interval with the houselight off. Responses to rewarded $(\mathrm{S}+)$ vocalizations resulted in $1 \mathrm{~s}$ access to food. Discrimination training continued until birds completed six 480-trial blocks with a discrimination ratio (DR) $\geq 0.80$ with the last two blocks being consecutive. For DR calculations see response measures, below.

Birds were randomly assigned to either a True category discrimination group $(n=12)$ or a Pseudo category discrimination group $(n=6)$. Black-capped chickadees in the True category discrimination group were divided into two subgroups: one subgroup discriminated 60 rewarded $(\mathrm{S}+)$ calls produced in fall from 60 unrewarded (S-) calls produced in spring (Fall S+ Group; three males and three female subject), while the other subgroup discriminated 60 rewarded (S+) calls produced in spring from 60 unrewarded (S-) calls produced in fall (Spring S+ Group; three males and three female subject).

The Pseudo category discrimination group was also divided into two subgroups. Each subgroup discriminated 30 randomly-selected rewarded $(\mathrm{S}+)$ calls produced in fall and 30 randomly-selected rewarded (S+) calls produced in spring from 30 unrewarded (S-) calls produced in fall and 30 unrewarded (S-) calls produced in spring (Total of 120 stimuli; Pseudo 1: two males and one female subject; Pseudo 2: two males and one female subject). The purpose of the Pseudo groups was to include a control in which subjects were not trained to categorize according to season.

\section{Discrimination $85 \%$}

This phase was identical to Discrimination training, except that the $\mathrm{S}+$ vocalizations were rewarded with a reduced probability (i.e., $p=.85$ ). On unrewarded $\mathrm{S}+$ trials, entering the feeder after the stimulus finished playing resulted in a $30 \mathrm{~s}$ intertrial interval, during which the houselight remained on, but there was no access to food. Discrimination 85 training was employed to introduce birds to trials in which there was no access to food, but the houselight remained illuminated, in order to prepare birds for transfer trials in which stimuli were neither rewarded, nor punished. Discrimination 85 training continued until birds completed two 480 -trial blocks with a DR $\geq .80$.

\section{Transfer Testing}

During Transfer testing, the stimuli and reinforcement contingencies from Discrimination 85 were maintained. In addition, 130 stimuli (50 Fall produced calls from novel individuals, i.e., TRS Fall 1; 50 Spring produced calls, i.e., TRS Spring; and 30 Fall produced calls from repeated individuals, i.e., TRS Fall 2) were introduced. These new (i.e., transfer) stimuli were each presented once during a 730trial block ( $\mathrm{S}+$ and S- stimuli from Discrimination 85 training were presented five times each; randomly- 
selected without replacement). Responses to transfer stimuli resulted in a $30 \mathrm{~s}$ intertrial interval with the houselight on, but no access to food; we did not differentially reinforce or punish transfer stimuli, and presented each transfer stimulus only once each per bin, so subjects did not learn specific contingencies associated with responding to these transfer stimuli. All birds completed a minimum of three blocks of Transfer trials and these were included for analysis. Following Transfer, birds were returned to their colony rooms.

One bird completed all training and testing but was found to be a statistical outlier in transfer testing as their bins to criterion exceeded three standard deviations from the group mean. This bird's data was removed from the data set for the statistical analysis of the transfer data.

\section{Response Measures}

For each stimulus exemplar, a proportion of response was calculated by the following formula: $\mathrm{R}+/(\mathrm{N}-\mathrm{I})$, where $\mathrm{R}+$ is the number of trials in which the bird went to the feeder, $\mathrm{N}$ is the total number of trials, and I is the number of interrupted trials in which the bird left the perch before the entire stimulus played. For Discrimination and Discrimination 85 training, we calculated a discrimination ratio (DR), by dividing the mean proportion of response to all $\mathrm{S}+$ stimuli by the mean proportion of response of $\mathrm{S}+$ stimuli plus the mean proportion of response of S- stimuli. A DR of .50 indicates equal responding to rewarded (S+) and unrewarded (S-) stimuli, whereas a DR of 1.00 indicates perfect discrimination. The DR was used as a criterion to reach, but not a measure used for analysis.

\section{Statistical Analysis}

An independent-samples $t$-test was run on the number of trials to criterion and DRs for the True and Pseudo category groups. We then ran a repeated measures ANOVA on the proportion of response to different stimulus types (DIS S+ and TRS S+; DIS S- and TRS S-) for both True and Pseudo groups. We also ran a repeated measures ANOVA on the proportion of response between transfer type (TRS Fall 1; TRS Fall 2).

\section{Results}

\section{Trials to Criterion}

We conducted an independent-samples $t$-test on the number of trials to reach criterion for the two True category conditions ( $\mathrm{S}+$ Fall group, $\mathrm{S}+$ Spring group) to determine if there were any differences in acquisition speed. There was no significant difference found, $t(10)=1.061, p=.314,95 \%$ CI $[-15.220$, 42.887]. We also did not find a significant difference between males and females, $t(10)=-0.579, p=$ $.088,95 \%$ CI [-37.977, 22.311].

We also conducted an independent-samples $t$-test on the number of trials to reach criterion for the two Pseudo category conditions (Pseudo 1 group, Pseudo 2 group) to determine if there were any differences in acquisition speed. There was no significant difference found, $t(4)=0.505, p=.640,95 \% \mathrm{CI}$ [-42.020, 60.687].

To compare the acquisition performance of the True and Pseudo category groups and to determine if True groups learned the discrimination in fewer trials than Pseudo groups, we conducted an independent-samples $t$-test on the number of 120-trial blocks to reach criterion for the True category and Pseudo category groups. There was no significant difference between the groups $(t(16)=-1.166, p=.261$, $95 \% \mathrm{CI}=[-36.407,10.574])$ in that True birds did not learn to discriminate significantly faster than Pseudo birds (Figure 2). We also did not find a significant difference between males and females, $t(16)=$ $0.201, p=.660,95 \%$ CI $[-20.982,25.383]$. 


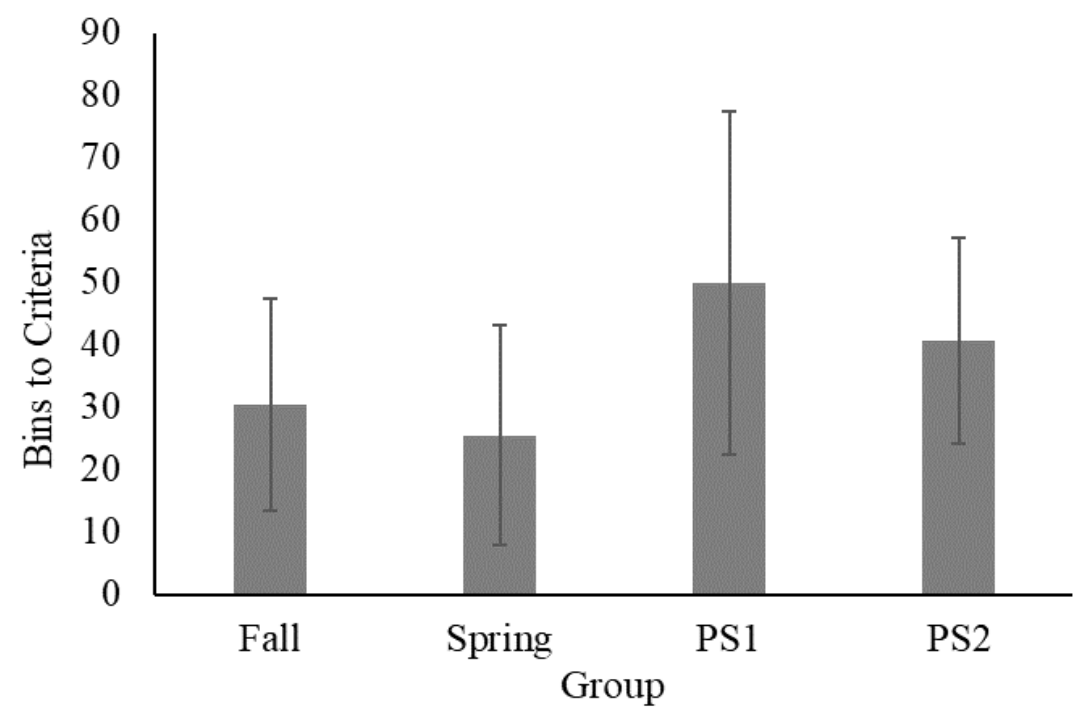

Figure 2. Number of bins needed to reach criteria during the DIS stage across all groups. Error bars are standard error of the mean (SEM).

\section{Category Learning}

A one-way ANOVA, excluding the outlier data, on the proportion of responding to the four stimulus types [Discrimination (DIS) S+ stimuli, Discrimination S- stimuli, Transfer (TRS) S+ associated stimuli, Transfer S- associated stimuli; excluding the TRS Fall 2 stimuli] by birds in the True Group did not find significance between season groups (Figure $3 ; F(1,9)=4.552, p=.062$ ). A one-way ANOVA on the proportion of responding to the four stimulus types [Discrimination (DIS) S+ stimuli, Discrimination S- stimuli, Transfer (TRS) S+ associated stimuli, Transfer S- stimuli; excluding the TRS Fall 2 stimuli] by birds in the Pseudo Group did not find significance between groups $(F(1,4)=4.147, p=.111)$.

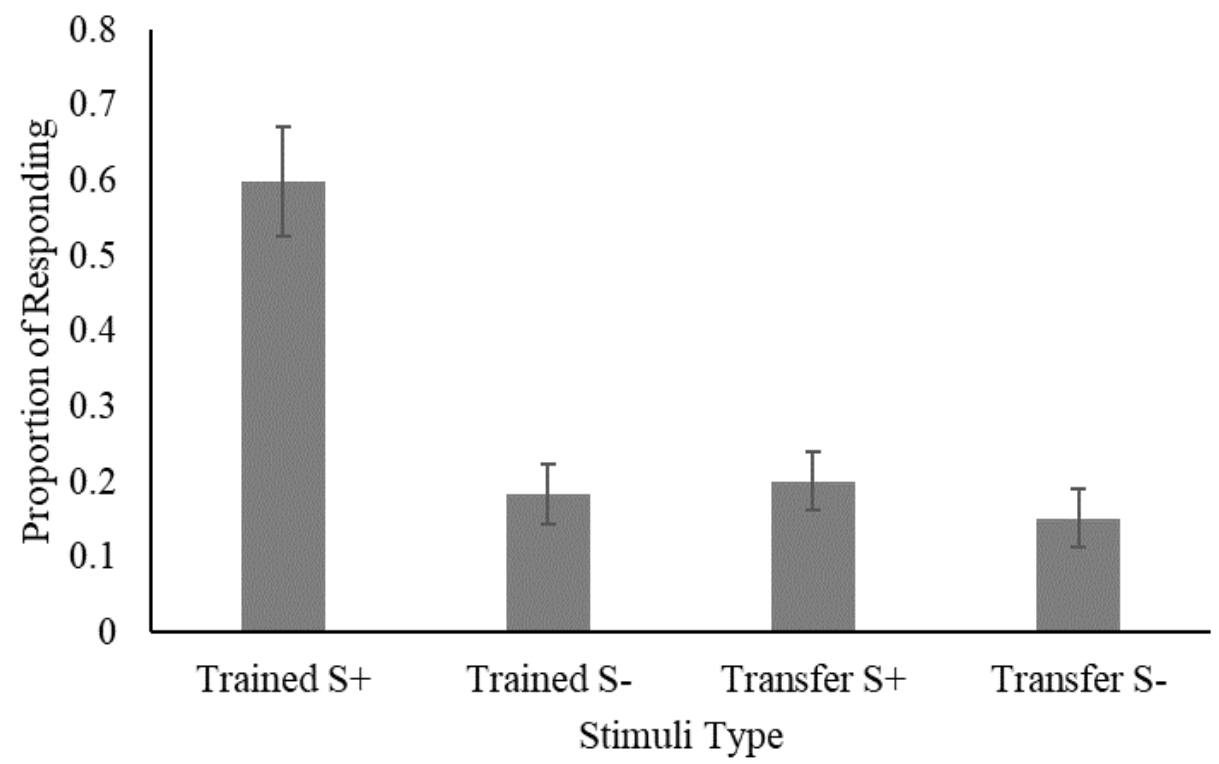

Figure 3. True Group proportion of responding to Trained and Transfer stimuli. Error bars are standard error of the mean (SEM).

Including the outlier data did not alter the results, with an ANOVA on the proportion of responding to the four stimulus types [Discrimination (DIS) S+ stimuli, Discrimination S- stimuli, 
Transfer (TRS) S+ associated stimuli, Transfer $\mathrm{S}$ - associated stimuli; excluding the TRS Fall 2 stimuli] by birds in the True Group did not find significance between groups $(F(1,10)=1.438, p=.258)$.

\section{Individual Learning}

In order to determine if chickadees would respond differentially to calls produced by the same individual in different seasons, using the learned category $(\mathrm{S}+$ ), we conducted a paired-samples $t$-test. The $t$-test compared responding to fall produced calls (Fall 2 stimuli), from individuals who also provided spring produced calls during the Discrimination Training phase, in both the S+ Fall group and the S+ Spring group. We did not find significance between groups $(t(24)=1.741, p=.094,95 \%$ CI $[-0.0136$, 0.161]). This suggests that the birds did not attend more to individual than season and treated all transfer stimuli the same.

\section{Discussion}

We found that while black-capped chickadees can learn to discriminate between the two groups of vocalizations, chick-a-dee calls produced in the fall versus spring, chickadees do not seem to naturally categorize these calls into "fall" and "spring" produced call categories. That is to say that there is nothing perceptually similar about the vocalizations produced in either the spring or fall that made them form spring-like or fall-like perceptual categories. We found no significant differences in the time to acquisition between the True and Pseudo groups (Figure 2), suggesting that birds learning a true category had no advantage over birds learning without a perceptual category. Additionally, we found no significant differences in responding to untrained calls, meaning there was no evidence of transfer of the categories learned in Discrimination (Figure 3). We also found no significant differences between responding to calls from the same individual and responding to separate individuals.

The lack of significant differences in acquisition between the True and Pseudo groups suggest that the black-capped chickadees used rote memorization, rather than categorization, to learn the task. The use of rote memorization as a mechanism to solve this task can also be supported by the fact that chickadees in the current study were unable to generalize their initial learning to novel stimuli. It is possible that using a larger stimulus set would cause the chickadees to rely on categorization rather than memorization (McGregor \& Avery, 1986); however, categorization by black-capped chickadees has been observed in similar behavioral tasks with smaller conspecific-produced stimulus sets (see Hahn et al., 2016) validating our methodology for testing categorization.

While little is known about whether or how the bioacoustics of chick-a-dee calls change across seasons, chickadees have been observed to change their behavior in response to these calls depending on season. Individual Carolina chickadees (Poecile carolinensis) attend to syntax, or note order, more in the fall and winter compared to the spring, likely due to the formation of flocks in the fall and winter with both conspecifics and heterospecifics (Clucas et al., 2004). As the syntax of the calls used in the current study was not manipulated in the stimuli used as it was in the Carolina chickadees study, it is likely that this effect was not present in the current study. Cells in the cochlea and brainstem of passerines have been shown to respond to sound differently depending on season (Lucas et al., 2007). Carolina chickadees, tufted titmice, and nuthatches all showed a seasonal effect on their neural responding to differences in frequencies and onset amplitude. Rodriguez-Saltos and colleagues (2018) demonstrated that hormones produced in response to calls were seasonally modulated in white-throated sparrows (Zonotrichia albicollis), an effect that would not have been seen in the current study as we only collected behavioral data. These changes across seasons suggest that perhaps black-capped chickadees also change which components of the chick-a-dee call they attend to dependent on season, rather than a bioacoustic change in the calls. Future studies could focus on how chickadee respond behaviorally and hormonally to certain note types across seasons.

Since we did not find that black-capped chickadees naturally categorize between calls produced in the fall versus spring during Transfer testing, it seems sensible to inquire if the calls differ acoustically, 
as a lack of acoustical differences would be consistent with a failure to categorize calls into perceptual categories. Using solely the calls presented in this study, our bioacoustic analysis did not find any differences between calls produced in the fall versus the spring, with the exception of number of total notes. With the lack of acoustic differences across seasons it suggests that the chickadees learn via memorization during the training phases. The lack of acoustic differences in calls would also explain why there was no generalization of the learned categories to the unlearned stimuli during the testing phase. Although we did conduct a general bioacoustic analysis of the calls used in this study, we did not look at acoustic differences in the note types specifically, which could aid in learning these individual calls. An unpublished study conducted following the completion of this experiment aimed to quantify bioacoustic differences between individual's calls across seasons (Campbell et al., unpublished) and demonstrated changes in the composition of calls produced by individual birds in spring as compared to the calls they produced in the fall (Figure 1). However, these individual differences were not observed to be consistent between birds such that the changes in composition observed in one bird were often different than that of another (i.e., some birds produced more A notes in spring than they did in fall, whereas others produced fewer A notes). While the unpublished study did not find consistent differences between individuals, it is possible that with a larger sample size, a species typical seasonal difference in call structure could be found. Future studies should explore more fully the bioacoustic differences across seasons as a species overall. In the current study, we aimed to examine if individual calls differed with season by presenting previously non-differentially rewarded calls produced by the same individuals as a trained call, but recorded in a different season. We found that chickadees responded the same to these novel calls as to those produced by novel individuals, suggesting that the chickadees were not responding to an individual any more than they were responding to season.

\section{Conclusion}

Overall, we found that black-capped chickadees do not categorize chick-a-dee calls produced in different seasons as distinct. While previous studies have shown behavioral, physiological, and hormonal differences in response to chick-a-dee calls across season, this experiment suggests that the calls themselves do not differ between spring and fall. Although we were able to successfully train chickadees to respond depending on season a call was produced, they did not generalize their training to novel stimuli, suggesting that seasonal information is not a natural factor attended to by these birds. In addition, calls produced by the same individual were treated similarly to those produced by other birds, regardless of the season calls were produced in. Thus, our findings provide evidence that black-capped chickadee chick-a-dee call production does not change between the seasons of spring and fall.

\section{Acknowledgements}

We would like to thank Al Dennington for his technical assistance.

This research was supported by a Natural Sciences and Engineering Research Council of Canada

(NSERC) Discovery Grant and Discovery Accelerator Supplement, an Alberta Ingenuity Fund (AIF) New Faculty Grant, a Canada Foundation for Innovation (CFI) New Opportunities Fund (NOF) and Infrastructure Operating Fund (IOF) grants along with start-up funding and CFI partner funding from the University of Alberta (UofA) to CBS.

\section{References}

Alward, B. A., Rouse Jr., M. L., Balthazart, J., \& Ball, G. F. (2017). Testosterone regulates birdsong in an anatomically specific manner. Animal Behaviour, 124, 291-298.

Avey, M. T., Hoeschele, M., Moscicki, M. K., Bloomfield, L. L., \& Sturdy, C. B. (2011). Neural correlates of threat perception: Neural equivalence of conspecific and heterospecific mobbing calls is learned. PLoS ONE, 6, e23844. 
Avey, M. T., Kanyo, R. A., Irwin, E. L., \& Sturdy, C. B. (2008). Differential effects of vocalization type, singer and listener on ZENK immediate early gene response in black-capped chickadees (Poecile atricapillus). Behavioural Brain Research, 188, 201-208.

Bradbury, J. W., \& Vehrencamp, S. L. (1998). Principles of animal communication. Sinauer.

Campbell, K. A., Dahal, R., Duia, S., \& Sturdy, C. B. (2016). Individual differences in black-capped chickadee (Peocile atricapillus) chick-a-dee call composition across time. [unpublished data]

Congdon, J. V., Hahn, A. H., Campbell, K. A., Scully, E. N., \& Mischler, S. K., (2019). Discrimination of high- and low-threat vocalizations: An examination of referential communication in black-capped chickadee (Poecile atricapillus) mobbing calls [Manuscript submitted for publication].

Clucas, B. A., Freeberg, T. M., \& Lucas, J. R. (2004). Chick-a-dee call syntax, social context, and season affect vocal responses of Carolina chickadees (Poecile carolinensis). Behavioral Ecology and Sociobiology, 57, 187-196.

Cynx, J., Bean, N. J., \& Rossman, I. (2005). Testosterone implants alter the frequency range of zebra finch songs. Hormones and Behavior, 47, 446-451.

Dutour, M., Cordonnier, M., Lena, J., \& Lengagne, T. (2019). Seasonal variation in mobbing behaviour of passerine birds. Journal of Ornithology, 160, 509-514.

Ficken, M. S., Ficken, R. W., \& Witkin, S. R. (1978). Vocal repertoire of the black-capped chickadee. Auk, 95, 3448.

Ficken, M. S., \& Witkin, S. R. (1977). Responses of black-capped chickadee flocks to predators. The Auk, 94, 156157.

Greenewalt, C. H. (1968). Bird song: Acoustics and physiology. Smithsonian Institution Press.

Griffiths, R., Double, M. C., Orr, K., \& Dawson, R. J. (1998). A DNA test to sex most birds. Molecular Ecology, 7, 1071-1075.

Hahn, A. H., Hoang, J., McMillan, N., Campbell, K., Congdon, J., \& Sturdy, C. B. (2015). Biological salience influences performance and acoustic mechanisms for the discrimination of male and female songs. Animal Behaviour, 104, 213-228.

Hahn, A. H., Hoeschele, M., Guillette, L. M., Hoang, J., McMillan, N., Congdon, J. V., Campbell, K. A., Mennill, D. J., Otter, K. A., Grava, T., Ratcliffe, L. M., \& Sturdy, C. B. (2016). Black-capped chickadees categorize songs based on features that vary geographically. Animal Behaviour, 112, 94-104.

Lucas, J. R., Freeberg, T. M., Long, G. R., \& Krishnan, A. (2007). Seasonal variation in avian auditory evoked responses to tones: A comparative analysis of Carolina chickadees, tufted titmice, and white-breasted nuthatches. Journal of Comparative Physiology A, 193, 201-215.

Mahurin, E. J., \& Freeberg T. M. (2009). Chick-a-dee call variation in Carolina chickadees and recruiting flockmates to food. Behavioral Ecology, 20, 111-116.

McGregor, P. K., \& Avery, M. I. (1986). The unsung songs of great tits (Parus major): Learning neighbours' songs for discrimination. Behavioral Ecology and Sociobiology, 18, 311-316.

Njegovan, M., Hilhorst, B., Ferguson, S., \& Weisman, R. (1994). A motor-driven feeder for operant training in song birds. Behavior Research Methods, Instruments, \& Computers, 26, 26-27.

Pyle, P. (1997). Identification guide to North American birds. Slate Creek Press.

Rodriguez-Saltos, C. A., Lyons, S. M., Sockman, K. W., \& Maney, D. L. (2018). Sound-induced monoaminergic turnover in the auditory forebrain depends on endocrine state in a seasonally-breeding songbird. Journal of Neuroendocrinology, 30, 1-10.

Shedd, D. H. (1983). Seasonal variation in mobbing intensity in the black-capped chickadee. The Wilson Bulletin, 95, 343-348.

Smith, S. M. (1991). The black-capped chickadee: Behavioral ecology and the natural history. Cornell University Press.

Sturdy, C. B., \& Weisman, R. G. (2006). Rationale and methodology for testing auditory cognition in songbirds. Behavioural Processes, 72, 265-272.

Templeton, C. N., Greene, E., \& Davis, K. (2005). Allometry of alarm calls: Black-capped chickadees encode information about predator size. Science, 308, 1934-1937. 